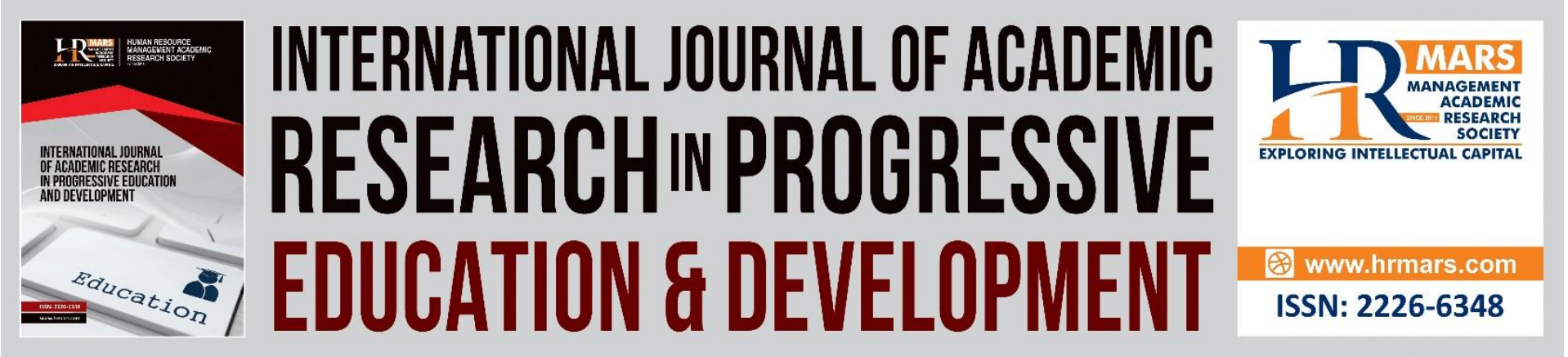

\title{
The Effectiveness of Cognitive Restructuring on Depression among University Students: Neo-CBT Case Study
}

\section{Nor Farahzulaikha Abdullah \& Mohammad Aziz Shah Mohamed Arip}

To Link this Article: http://dx.doi.org/10.6007/IJARPED/v10-i4/10559

DOI:10.6007/IJARPED/v10-i4/10559

Received: 09 September 2021, Revised: 10 October 2021, Accepted: 30 October 2021

Published Online: 26 November 2021

In-Text Citation: (Abdullah \& Arip, 2021)

To Cite this Article: Abdullah, N. F., \& Arip, M. A. S. M. (2021). The Effectiveness of Cognitive Restructuring on Depression among University Students: Neo-CBT Case Study. International Journal of Acdemic Research in Progressive Education and Development, 10(4), 99-106.

Copyright: (c) 2021 The Author(s)

Published by Human Resource Management Academic Research Society (www.hrmars.com)

This article is published under the Creative Commons Attribution (CC BY 4.0) license. Anyone may reproduce, distribute, translate and create derivative works of this article (for both commercial and non-commercial purposes), subject to full attribution to the original publication and authors. The full terms of this license may be seen at: http://creativecommons.org/licences/by/4.0/legalcode

Vol. 10(4) 2021, Pg. $99-106$

Full Terms \& Conditions of access and use can be found at http://hrmars.com/index.php/pages/detail/publication-ethics 


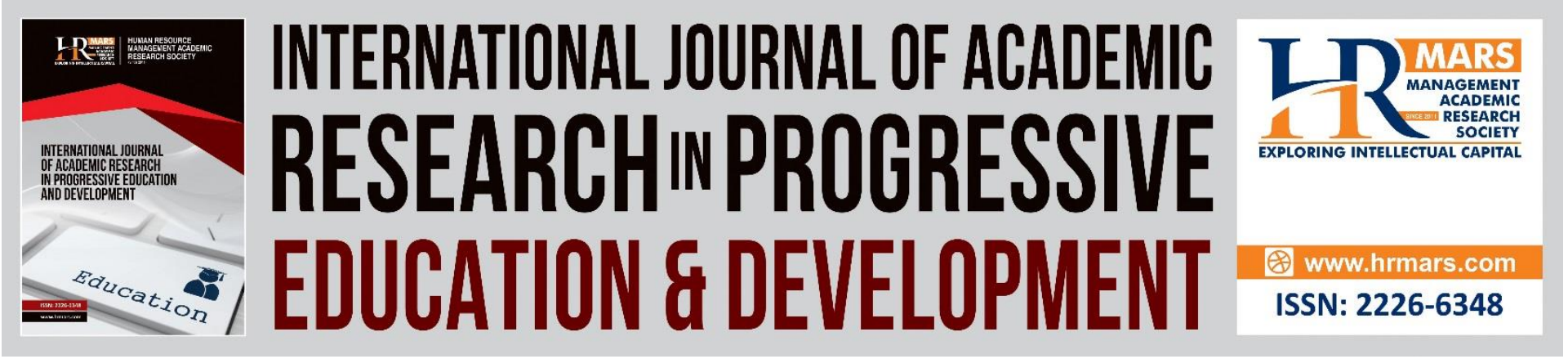

\title{
The Effectiveness of Cognitive Restructuring on Depression among University Students: Neo-CBT Case Study
}

\author{
Nor Farahzulaikha Abdullah \& Mohammad Aziz Shah \\ Mohamed Arip \\ Faculty of Human Development, Universiti Pendidikan Sultan Idris, Tanjung Malim, Perak \\ Email: farahzulaikhaa98@gmail.com
}

\begin{abstract}
Nowadays, depression is one of famous mental disorder among university students.This proven by National Institute of Mental Health (2012) many people experience the first symptom of depression during their college years or in other word, young adult years, but many depressed college students are not seeking the help they need. In 2011, about 30 percent of college students were reported feeling so depressed that it was difficult for them to sometimes function (American College Health Association (ACHA), 2012). This research aims to study the effectiveness of cognitive restructuring techniques university students that experienced depression. This qualitative study uses a case study approach on three students of university students in Malaysia who are suffering from depression. The purpose of this research are i) to identify the thought patterns of students expriencing depression ii) to apply the cognitive restructuring technique to reduce depression among university students iii) to identify effect of the cognitive restructuring technique on feelings and behaviour. The research using this purposive sample consists of three students conducting an interview with the researcher. Partially structured interviews were conducted to see the effectiveness of cognitive restructuring techniques. In addition, observations were also conducted during the interview session. Data forms analyzed using thematic analysis.The findings show that five themes are derived from the research question namely factors of depression, symptoms of depression, negative thoughts, positive thoughts and cognitive restructuring reflections. This study provides implications for counselors and trainees in handling depression cases by applying cognitive restructuring techniques.
\end{abstract}

Keywords: Cognitive Restructuring, Depression, University Students, Neo-Cognitive Behavioral Theraphy, Case Study

\section{Introduction}

Depression is one of mental disorder. Depression (major depressive disorder) is a common and serious medical illness that negatively affects how you feel, the way you think and how you act. Nowadays, depression is one of famous mental disorder among university 
students.This proven by National Institute of Mental Health (2012) many people experience the first symptom of depression during their college years or in other word, young adult years, but many depressed college students are not seeking the help they need. In 2011, about 30 percent of college students were reported feeling so depressed that it was difficult for them to sometimes function (American College Health Association (ACHA), 2012). Depression among university students affect emotions, study and also can make their behavioural changes when they try handling their depressed. Depression can make student feel like hopeless, loneliness and finally can lead to suicide as the best way handling their problems.

Neo-CBT theory is a theory founded on Profesor Dr. Mohammad Aziz Shah Mohamed Arip. Neo is derived from the Latin language which means new (baharu) This theory was originally derived from CBT theory but was renewed into Neo-CBT theory. Cognitive Behavioral Therapy is one of psychotherapy that developed by Aaron T. Beck who is American Psychiatrist. Aaron T. Beck was born on 18 July 1921 in Providence, Rhode Island. Beck was focus on the clients and helping clients identify their negative thoughts and changes them to more realistic about what they thoughts. Successfully treating any disorder, Beck found involved making patients aware of these negative thought patterns. This approach to treatment eventually became known as cognitive behavioral therapy (Fenn \& Bryne, 2013).

Cognitive restructuring is a technique on cognitive behvaioral therapy to changes the negative thought of people and replace to the positive thoughts. The technique can be applied on someone who is stressed by painful emotion and has harmful behaviour for him and others, who uses absolute languages (always, must, and never), and who has a belief system that impedes the progress of himself (Corcoran, 2006).

Related to the effort to improving depression on university students, this study used cognitive structuring technique which has several advantages we can see while using this technique.The basic concept of cognitive restructuring counseling is based on emotive rational counseling in which human is born with potential both to think rationally and honestly and to think irrationally and badly and tends to take care of himself, happily to think, loves, socializes with others, grows and develops his potential (Corey, 2012). So the objective of this research are (i) To identify the thought patterns of students expriencing depression. (ii) To apply the cognitive restructuring technique to reduce depression among university students. (iii) To identify effect of the cognitive restructuring technique on feelings and behaviour.

\section{Methodology}

The qualitative method that used in this research is case study. The purposive sampling method was used to collect from university in Malaysia who are suffering from depression. The sample selected in this research are those who still studying in Universiti Pendidikan Sultan Idris (UPSI). The sample involved in the interview are Researcher using thematic analysis to make analysis of the data obtained.

There are several types in applying cognitive restructuring. The first step, identify the triggering event which is something often happens in partcipants external environment and identify the scale of participants depression on that time. Second, researcher will identify the negative thought of participant and also identify the effect on their behaviour and feelings. Third is applying cognitive restructuring on the session. For this step, research will dispute the negative thought into the positive thoughts and identify the effect on behaviour and feelings of the participants. Lastly is refelction from participants after having this techinuque. 


\section{Findings}

The purpose of this research are i) to identify the thought patterns of students expriencing depression ii) to apply the cognitive restructuring technique to reduce depression among university students iii) to identify effect of the cognitive restructuring technique on feelings and behaviour.

\section{Objective 1: To Identify the thought Patterns of Students Experiencing Depression}

Based on the result of the analysis of the interviews conducted with participant 1 , the researcher was able to explore the the lack of attention is the factor of depression for participants 1. Based on the interview session with participants 1, the researcher found that she is victim of bullying since in high school. She has a sense of fear of socializing with others. She will also blame himself when this happens to her. This means she will not blame others when something bad happens to herself and she also has a feeling of not loving herself.

Researcher identify the negative thoughts means a thought generated by participants when dealing with depression. In the interview session, the participants had created a negative thought that could relate to themselves when facing depression and also identify on behaviour and feelings.

"I feel sad because no one understands me and they are just kind of pretend to understand and at the same time they actually say I am fake. Examples of when I'm sad to be so I guess they don't love me, they kind of have to because there's a blood relate hrmm "

"I'm kind of sad...it's kind of like I can't feel like someone else's main familial feel. Why my family is second, third, kind of a person who is a last person for me to wish I had a feel." "hrmm my actions sit still."

( Participant 1 )

Participant one feel sad and want to be alone

Next, researchers have found participant 2 have an environment factor as a factor of depression. Participant 2 are the final semester students and stay at college. For this theme which is environment factor means this participants got less support from people around her such as lecturer and classmates. Participant 2 feels people around him do not understand herself and bring pressure to her. She also trigger when the people around him ask about assigment that need to be done. Participant 2 also feel burdened when her supervisor do not pay attention or tutoring completely in helping her to help assigment. The researcher found that participants 2 had problems with preparing all the tasks but did not get support and motivation from people around.

The negative thoughts and the effect on feeling and behavor had identified by researcher "I am very sad because of the burden of duty and my environment does not understand me." "My feeling is that I feel bad, I feel like I'm just being cried all the time."

"My behavior.. I sit in the room. Sometimes I lock the door, I sit down. I'm alone in my room." ( participant 2 )

Next, the lost of significance people is the factor of depression for participant 3 . The loss of significance people in her life has caused her to feel lost place to complain or share problems. Until now, the participant 3 still cannot forget the story and have an impact on her lives.The researcher found that the participant 3 were still unable to accept the loss of her significance people even though the person was not part of her family. However that people is often the place where she complains about her problems. 
Researcher had identified the negative thoughts and the effect on feelings and behaviou based on the participant's event.

"I think I'm very sad, I have nowhere to share my problems in my village"

"Sad..im sad very much whenever $C$ has a problem. If there is a problem i will meet him, but when he is not around so I am feel like a close story, who wants to hear it. "

" $C$ if it feels that way again when $C$ is in trouble, $C$ will not sit near anyone's area..C will not sit in family C. I mean when my parents is sitting in the living room, $C$ will avoid people. $C$ don't want people know Chas that feel until now."

( participant 3 )

\section{Objective two: To apply the cognitive restructuring technique to reduce depression among} university students.

Based on second objective, the researcher came up with one theme which is positive thoughts. After the researcher identified the negative thoughts of participants, the researcher used cognitive structuring techniques to get positive thoughts when dealing with depression.Participants are required to make a positive thought that is very related to themselves. Researcher have helped participants to generate positive thoughts.

".haaa even i am sad, depressed but actually I'm happy too with my life like my circle friend so little so I can believe and can't believe it...then aboutt my family, even they are straight forward, sometimes painful but at the same time teaching me to accept reality."

( Participant 1 )

"Haa though I feel sad but actually I know my friends understand me and want to support me. Want to motivate me so I can prepare fyp, can set up assigment"

( Participant 2 )

"Although I feel sad about what it is but in fact I still have my own father to share the problem" ( partcipant 3 )

Researcher also identified the effect on feelings and behavior of participants after applying cognitive restructuring.

"a little open..ouh actually my life is not very bad pon."

"Strengthen our spirit even sad, feel depressed but it doesn't bother my pound to succeed.."

"She feels like ouhh okay don't give up with your life and don't be like that. you need to continue your life for the rest of your life..continue"

( Participant 1)

"Actually when I make that kind of verse, I'm more positive I feel like a relief. In fact the burden is not that great..haaa is the only one I don't know about myself that time."

"Okay I think I want to start hanging out with people"

( participant 2)

" $C$ feels what $C$ was saying was wrong in $C$. It means $C$ is in a sense of self-esteem $C$. it feels like $C$ can accept it. Like the negative thing to the something that $C$ itself feels causes $C$ to accept."

"Feel relieved ..C don't feel like I can't do that. C doesn't feel that way. C think $C$ can do it because it coming out of $C$ itself."

"C cannot want to avoid family C, it is best to tell my father. Need to share with people so that people know what $C$ feels. So $C$ is not alone in dealing with that matter by my own."

(participant 3) 


\section{Objective three: to Identify Effect of the Cognitive Restructuring Technique on Feelings and Behaviour}

Objective 3 is to know the effectiveness of cognitive restructuring towards depression's students.The researcher described the use of cognitive restructuring throughout the interview session. Participants presented a reflection on the use of cognitive restructuring after the completion of the interview session.

Participant 1 described this cognitive restructuring technique as affecting herself as she was able to disputed the negative and positive thinking. The participant also felt that the positive thoughts generated greatly affected herself.

"What kind of technique is this, it feels like when we can say the negative thing, why are you so negative, it is such a feeling but there is a sense of right with me.. when covert to positive so I feel like it is okay to see what I am dissatisfied with and satisfied with. look like a positive and negative side."

"It makes an impression.."

(participant 1)

The third participant also stated that this cognitive restructuring was helpful to individuals with negative thoughts. He also states that when a person has a positive mindset it will make one change for the better.

"Okay haa what $C$ can say in relation to cognitive restructuring techniques. For $C$ the technique is very helpful for individuals with a negative mindset. I mean like C himself at first $C$ haa is not positive. $C$ is in a situation where $C$ is in a negative mind. So the negative thing is that $C$ feels like i am alone. But with this technique $C$ feels that someone in the negative phase of thinking can change in a better direction in a more positive way. So it doesn't hurt yourself. For $C$ the technique is very useful for $C$ because $C$ believes something happen in ourself is starting with our thinking."

(participant 3)

\section{Discussion}

The findings show that participants with depression have negative thoughts. This is because they often think about the problem that greatly affects their behavior and feelings. This proven by Rose Fazilah Ismail, Rusdi Abd. Rashid, Zahari Ishak \& Haris Abd. Wahab loss of ability to think or to focus (focus) Individuals with depression also often experience symptoms such as difficulty in rational thinking in making a decision and individuals are easily distracted. Major depression disorders can also be detected when individuals present symptoms of irrational feelings such as despair, guilt and often misinterpret the failure of something or event over their own weaknesses (APA, 2013).

The findings of this study found that these negative thoughts occur when they face situations that result in depression, namely lack of attention, environmental factor and lost of significance student. The depression they face will affect their feelings as well as their behavior. The findings show that participants will experience extreme sadness and also want to be alone. These sad feelings can occur over a long period of time either throughout the day and can last for weeks (WHO, 2017). Generally, the disruption experienced interferes with the social functioning of individuals and results in deterioration in the social, occupational and other aspects of individual functioning (WHO, 2017).

The results of an interview using cognitive restructuring techniques show that participants can convert negative thoughts to more positive thoughts. Cognitive restructuring 
technique focuses its attention on the effort of identification and changes negative thoughts or opinion in oneself and irrational clients' beliefs into positive and rational thoughts (Nursalim, 2013). The positive thoughts generated can affect the participants' feelings and behaviors. Positive thinking is very important for people with depression to ensure that their behavior does not negatively affect them.

Based on the interview sessions conducted to the participants, the level of depression faced by the participants decreased from the beginning of the session. This technique is designed to help to reach out better emotional responses by changing the common habit of habitual assessment to be unusual on (Efrord, 2016). This shows that cognitive restructuring techniques can solve depression.

The researcher received feedback from participants who stated that this cognitive restructuring technique was very effective and appropriate for individuals with depression. Based on the feedback of the participants also, their feelings and their behavior changed in a more positive way and it showed that cognitive restructuring techniques were able to compensate for the feelings and behaviors for those who are having depression. This proven by Johnco et al (2015) that said that cognitive restructuring is a CBT technique that involves learning to identify and dispute unhelpful/ irrational thoughts in order to generate more adaptive ways of thinking and responding.

\section{Conclusion}

In the conclusion, the cognitive restructuring is one of the technique that can reduce depression. Researcher has received positive feedback from the participants when using cognitive restructuring techniques. This is because cognitive restructuring has produced a positive mind when it comes to depression. This is especially true for individuals with negative thoughts. Positive thinking is often created to provide positive feelings and behaviors that do not harm individuals with depression. The researcher also provided some suggestions for researchers who wish to conduct a research in future. This research sample focused on students of Univerisiti Pendidikan Sultan Idris. For future research, the researcher may expand the research sample by engaging other university students. Researchers can also look at the effectiveness of this technique for students with depression. Therefore, counselors can look at the effectiveness of this cognitive restructuring technique compared to current studies that only look at students of University Pendidikan Sultan Idris. Recent research have focused this cognitive restructuring technique on individuals with depression. For future research, the researcher may apply this research to individuals with mental health problems. This is because the cognitive restructuring technique is a simple and fast technique to apply.

\section{References}

American College Health Association. (2012). American College Health Association National College Health Assessment II: Reference group executive summary (Fall 2011 ed.). Hanover, MD: American College Health Association.

Corcoran, J. (2006). Cognitive-Behavioral Methods: A Workbook for Social Workers. Upper Saddle River, NJ: Pearson.

Corey, G. (2012). Theory and practice of group counseling (8th ed.). Boston, MA:Brooks/Cole.

Efrord, B. T. (2016). 40 Techniques to Know Each Constituent. Yogyakarta: Student Library 
Fenn, K., \& Byrne, M. (2013). The key principles of cognitive behavioral therapy. InnovAiT: Education and Inspiration for General Practice, 6(9), 579-585. https://doi.org/10.1177/1755738012471029

Johnco, C., Wuthrich, V. M., \& Rapee, R. M. (2015). The Impact Of Late-Life Anxiety And Depression On Cognitive Flexibility And Cognitive Restructuring Skill Acquisition. Depression and Anxiety, 32(10), 754-762. https://doi.org/10.1002/da.22375

Nursalim, M. (2013). Intervention and Conseling Strategies. Jakarta: PT. Index

Schlebusch, L., Burrows, S., \& Wada, N. (2009). Suicide prevention and religious traditions on the African Continent. In D. Wasserman \& C. Wasserman (Eds) Suicidality and suicide prevention. A global perspective. Oxford, England. Oxford University Press.

World Health Organization. (2017). Depression and Other Common Mental Disorders: Global Health Estimates. Geneva: World Health Organization. 